\title{
Pemanfaatan Behavior Tree dan Fuzzy Waypoint Tactic pada Game Strategi "War of Zombies"
}

\author{
Michael Patria Christie, Departemen Informatika, Institut Sains dan Teknologi Terpadu Surabaya, \\ Andreas, Fakultas Ekonomi dan Bisnis, Universitas Pelita Harapan
}

\begin{abstract}
Abstrak - Dalam video game jaman sekarang, hampir semua permainan memakai kecerdasan buatan sebagai cara agar non-player karakter agar dapat berinteraksi dengan game. Karena itu pada penelitian ini bertujuan untuk mencoba menerapkan kecerdasan buatan behavior tree dan juga Fuzzy waypoint tactic. Project game "War of Zombies" ini merupakan permainan strategi dimana pemain yang berperan sebagai zombie mencoba melenyapkan manusia sebagai musuhnya. Pada permainan ini selain waypoint tactic dan behavior tree terdapat beberapa metode kecerdasan buatan yang diterapkan seperti $A$ * pathfinding, djikstra dan juga fuzzy logic. Behavior tree merupakan metode panduan berisi langkah-langkah bagi karakter untuk menyelesaikan suatu tugas. Sedangkan fuzzy waypoint tactic merupakan cara bagi developer untuk memberitahu lokasi-lokasi strategis yang dapat membantu karakter dalam menyelesaikan tugas, seperti misalnya bersembunyi atau menembak. Pada game bertema strategi seperti ini, fuzzy logic sangat membantu untuk membuat suatu keputusan bagi karakter. Selain itu, fuzzy logic juga merupakan metode yang baik dalam waypoint tactic untuk menentukan lokasi strategis yang paling menguntungkan diantara pilihan-pilihan lokasi yang telah disediakan. Behavior tree juga merupakan metode yang baik dalam mengatur perilaku setiap karakter yang ada pada game strategi.
\end{abstract}

Kata Kunci- Artificial Intelligent, Behavior Tree, Djikstra, War of Zombies, Waypoint Tactics.

\section{PENDAhUluan}

$\mathrm{P}$ ERKEMBANGAN teknologi yang sangat pesat akhir-akhir ini membawa banyak perubahan dalam perkembangan perangkat lunak, salah satu jenis perangkat lunak yang sangat populer dewasa ini adalah game, game merupakan perangkat lunak yang digunakan sebagai sarana hiburan oleh siapapun tanpa memandang status, usia maupun gender. Salah satu fitur yang umum dan dapat ditemui pada hampir semua game yang ada pada zaman sekarang adalah Artificial Intelligence atau AI, AI adalah kepintaran buatan yang dipasang pada sistem komputer sehingga membuat player dapat bermain melawan komputer seolah-olah sedang melawan player lain.

Michael Patria Christie, Department of Informatics, Institut Sains dan Teknologi Terpadu Surabaya, Surabaya, Jawa Timur, Indonesia (e-mail: mpatriac@gmail.com)

Andreas, Department of Management, Faculty of Economy and Business, Universitas Pelita Harapan, Surabaya, Jawa Timur, Indonesia (e-mail: andreas.jodhinata@gmail.com
AI merupakan system yang menentukan bagaimana komputer tersebut berpikir sehingga hal ini sangat menarik jika diterapkan pada karakter musuh maupun karakter pembantu agar karakter tersebut dapat memilih dan menyesuaikan tindakan apa yang tepat pada situasi yang terjadi dalam game dan tidak terlihat berperilaku secara asal-asalan.

Semisalnya saja, kapan karakter musuh mulai menyerang dan juga bagaimana cara menyerang pemain? Apakah ketika karakter musuh berada di belakang pemain atau hanya ketika pemain tersebut menyerang pemain lain? Kondisi semacam itulah yang wajib ditentukan oleh developer dalam menentukan sebuah AI yang baik dan bagus. Apabila kualitas AI pada karakter kurang baik maka kualitas pada game tersebut akan turun. Karena itulah AI pada game juga dapat menentukan kualitas pada game.

Penelitian ini merupakan penerapan dua jenis Artificial Intelligence, yaitu Behavior Tree dan Fuzzy Waypoint Tactics, pada karakter musuh dan karakter pembantu milik musuh dalam sebuah game bernama War of Zombies. Sehingga musuh dapat memilih dan menyesuaikan tindakan-tindakan yang diambil berdasarkan kondisi yang ada. Mulai dari menentukan jenis serangan musuh terhadap karakter player berdasarkan lingkup jarak karakter, dimana posisi yang baik untuk bersembunyi, sampai pada menentukan kapan dan bagaimana karakter pembantu melakukan tugasnya atau kabur.

\section{TEORI PENUNJANG}

\section{A. Artificial Intelligence}

Artificial Intelligence atau Kecerdasan Buatan [1] adalah kecerdasan yang dimiliki oleh mesin yang dapat bertindak seperti layaknya manusia. Pada game, AI bertindak dalam mengendalikan karakter musuh dan karakter pembantu dari musuh agar dapat bermain melawan player.

\section{B. Behavior Tree}

Behavior tree [2]-[5] adalah suatu model matematis berbentuk tree yang dibuat untuk merepresentasikan perilaku dari suatu entitas yang diprogram. Behavior tree adalah sesuatu yang sangat fundamental dalam pengembangan game. Behavior tree mirip dengan finite state machine, hanya saja tidak seperti finite state machine yang berisi keadaan-keadaan, behavior tree berisi kumpulan instruksi dan perintah yang harus dijalankan oleh developer karena 
behavior tree mudah dimengerti oleh manusia sehingga tingkat kesalahan yang dibuat menjadi minimum.

\section{Waypoint Tactics}

Pada pathfinding, waypoint [6] biasanya lebih dikenal dengan sebutan representative point atau node. Developer akan menaruh waypoint sebagai cara untuk memberitahu karakter area yang bisa dilewati. Lalu untuk mengetahui rute terdekat maka tiap koneksi antar waypoint akan diberi bobot seperti jarak atau waktu, dan developer akan menggunakan algorithma seperti djikstra atau $\mathrm{A}^{*}$ untuk mencari rute terdekat [7].

\section{Panda BT}

Panda BT merupakan scripting framework behavior tree untuk unity. Framework ini memungkinkan untuk menentukan logika yang kompleks, skalabel dan dapat digunakan kembali dalam pembuatan game. Panda behavior diaplikasikan sebagai komponen pada gameobject. Komponen ini dapat dipasang pada segala gameobject untuk membuat behavior yang terdiri dari kombinasi C\# dan BT scripts yang dapat ditulis dengan menggunakan bahasa bawaan yang minimalist.

\section{DESAIN GAME}

\section{A. Informasi Umum}

Game war of zombies ini merupakan game dengan genre strategi seperti age of empire atau total war three kingdoms. Game ini adalah permainan single player dimana player akan melawan karakter dengan kecerdasan buatan. Game ini berbasis platform desktop windows. Konsep desain pada game ini adalah menggunakan konsep gambar dua dimensi. Game akan dibuat dengan menggunakan unity sebagai physic game engine dan juga visual studio sebagai code editor. Target usia untuk game ini adalah remaja berumur 13 tahun sampai 20 tahun.

Pada game ini terdapat 2 jenis karakter yaitu karakter zombie dan manusia. Setiap jenis pada karakter zombie dan manusia memiliki tipe yang berbeda beda. Yang akan dimainkan oleh player adalah karakter zombie. Dan yang akan menjadi musuh adalah karakter manusia. Berikut penjelasan setiap karakter yang dipakai pada game war of zombies.

- Karakter utama

Player adalah zombie pertama yang memiliki kesadaran dan kecerdasan. Player merupakan zombie yang berhasil menularkan kesadaran dan kecerdasan tersebut ke zombie yang lain. Karena itu, player diberikan peringkat teratas oleh zombie-zombie lain sebagai zombie leader. Sebagai zombie leader, player dapat membuat strategi dan menerapkannya dalam game. User dapat membuat unit dan mementukan zombie yang berada pada unit tersebut dan memberikan perintah melalui ghost general yang berfungsi sebagai pemimpin dalam setiap unit.

\section{- Ghost General}

Ghost general merupakan pemimpin sebuah unit. Player dapat memberikan perintah ke setiap unit melalui masing-masing ghost general pada setiap unit. Setiap unit akan terdapat 1 ghost general. Ketika user menambahkan unit, ghost general akan otomatis ditambahkan dalam unit.

Ghost general merupakan sarana bagi player untuk dapat memberikan perintah kepada setiap team. Ghost general hanya dapat berjalan dan dapat menyerang. Namun walaupun tidak dapat menyerang, ghost general tidak dapat diserang oleh musuh menggunakan apapun. Untuk mengalahkan ghost general, seluruh zombie pada team yang dipimpin oleh ghost general tersebut harus dikalahkan semua. Barulah ghost general akan mati.

- Iron Zombie

Iron zombie adalah zombie yang memiliki badan seperti slime karena karekteristik badannya. Iron zombie memiliki karakteristik seperti magnet. Sehingga badannya yang tertutupi oleh pasir besi, sehingga membuat bentuknya seperti slime. Karena badannya yang tertutupi oleh besi, iron zombie memiliki darah dan pertahanan yang cukup besar sehingga sangat cocok untuk melindungi zombie-zombie lain. Iron zombie juga memiliki kemampuan untuk mengubah bentuk pasir-pasir besi yang mengelilingi tubuhnya sesuai yang dia inginkan.

Iron slime tidak memiliki kemampuan untuk menyerang musuh. Namun sebagai gantinya iron slime memiliki darah yang tebal. Ketika perintah defend diberikan, maka iron zombie akan berubah menjadi seperti dinding. Dengan begitu akan memberikan perlindungan kepada karakter-karakter zombie yang lain dengan lebih efektif.

- $\quad$ Suicide zombie

Suicide Zombie adalah zombie yang berasal dari mayat teroris. Kegemarannya dalam meledekan bomb terbawa hingga mati. Badannya dapat mengeluarkan sebuah cairan enzim. Cairan tersebut merupakan gabungan dari zat-zat kimia yang cukup mudah meledak. Tubuhnya yang dapat dengan mudah terbakar dapat membuat ledakan cukup besar di area tersebut, dan memberikan damage yang cukup besar.

Apabila ghost colonel memberikan perintah untuk menyerang, maka suicide zombie akan pergi ke area yang ditentukan. Ketika sampai di tempat atau target yang ditentukan, maka akan muncul ledakan dengan jarak yang luas dan damage yang besar. Karena karakteristiknya, suicide zombie hanya dapat melakukan serangan hanya satu kali. Setelah melakukan serangan, suicide zombie akan langsung meninggal karena satu-satunya tipe serangan yang bisa dilakukan oleh suicide zombie adalah bom bunuh diri.

- Zombie gunner

Zombie gunner adalah zombie yang terlahir dari prajurit yang sudah meninggal dan dipersenjatai dengan pistol. Senjata yang biasa digunakan adalah senjata riffle buatan Russia yaitu AK-47. Karena ketika masih hidup mereka adalah prajurit, maka mereka memiliki kemampuan yang setara dengan prajurit manusia. 
Mereka memiliki kemampuan menembak yang sangat baik sehingga dapat menjadi ancaman bagi manusia.

Ketika ghost general memberikan perintah untuk menyerang, maka zombie gunner akan mengeluarkan riffle AK-47 dan mulai menembak target yang telah ditentukan. Ketika musuh sudah meninggal, maka zombie gunner akan berdiam diri sampai ada perintah selanjutnya. Namun apabila ghost general memberikan perintah massacre kepada zombie gunner, maka zombie gunner akan pergi menuju mendekati target lalu mulai menyerang hingga target meninggal dan akan mencari target lainnya secara otomatis hingga perintah untuk regroup diberikan.

- Blacksmith

Blacksmith adalah karakter manusia yang berfungsi untuk membetulkan sesuatu. Seperti misalnya sandbag, atau tembok yang berfungsi untuk melindungi manusia lain dari serangan zombie. Sayangnya, karena mereka tidak ahli dalam menembak, mereka tidak diberikan senjata sama sekali. Namun dengan tidak diberikan senjata, mereka dapat membawa muatan bahan baku lebih banyak untuk membetulkan tembok atau pintu.

Dalam game, blacksmith akan menuju ke tempat dimana tembok atau sandbag yang terkena damage. Ketika sudah di lokasi, blacksmith akan membetulkan tembok dan sandbag yang terkena serangan. Sandbag dan tembok yang hancur tidak dapat dibetulkan sama sekali. Ketika tidak ada lagi yang dibetulkan, maka blacksmith akan pergi ke tempat bersembunyi untuk menghindari serangan musuh. Ketika markas sudah ditembus oleh zombie, blacksmith akan lebih focus ke melarikan diri daripa melakukan tugasnya untuk membetulkan dinding atau pintu markas.

- Doctor

Doctor memiliki tugas untuk menyembuhkan orang yang terluka. Doctor akan pergi kesana kemari untuk menyembuhkan setiap karakter yang terluka. Karena lebih ahli dalam bidang kesehatan, doctor tidak memiliki pengetahuan mengenai cara menembak dan lain-lain. Karena itu doctor tidak memiliki kemampuan untuk menyerang.

Setiap area biasanya mempunyai 1-2 dokter. Dalam game, kemampuan doctor mirip dengan blacksmith. Doctor akan pergi menuju lokasi soldier yang terluka dan mulai menyembuhkan pasien. Setelah pasien sembuh, doctor akan pindah lokasi dan menyembuhkan pasien lainnya. Dokter tidak bisa menyembuhkan doctor lain, yang difokuskan untuk disembuhkan oleh doctor adalah soldier karena soldier memiliki tugas untuk menyerang zombie. Doctor tidak memiliki kemampuan untuk menyerang zombie. Ketika markas berhasil ditembus zombie, maka doctor akan pergi melarikan diri dari kejaran zombie. Ketika tidak sibuk menyembuhkan soldier, doctor akan pergi untuk bersembunyi.

\section{- Soldier}

Soldier merupakan prajurit yang telah dipersenjatai. Soldier memiliki kemampuan yang mirip dengan zombie gunner. Hanya saja soldier juga memiliki senjata lain yaitu pisau. Sehingga membuat karakter ini tidak hanya baik dalam serangan dekat, namun juga serangan jauh. Dalam game, soldier akan pergi ke lokasi yang dirasa cocok untuk menembak dan juga bertahan.
Soldier akan menuju lokasi yang menguntungkan dimana terdapat cover dan penglihatan yang bagus untuk menembak. Ketika terdapat zombie yang mendekat, maka soldier akan mengeluarkan pisaunya untuk menyerang zombie secara dekat.

Pada game ini, soldier terbagi menjadi dua team yaitu, defend team dan mobile team. Defend team memiliki tugas untuk melindungi area yang ditugaskan. Sedangkan mobile team merupakan team yang berfungsi untuk membantu area lain menyerang zombie. Hampir di setiap stage, akan terdapat soldier yang ditugaskan sebagai mobile team. Tugas dari mobile team adalah sebagai bala bantuan untuk team-team lain yang kesusahan dalam menangkis serangan zombie. Tidak seperti mobile team, defend team tidak dapat pergi ke lokasi yang lain selain yang ditentukan.

\section{B. Gameplay}

Seperti yang diberitahukan di informasi umum, game war of zombies merupakan game dua dimensi dan memiliki genre strategi. Game ini memaki top up view dimana player melihat situasi lapangan dari atas. Konsep ini membantu agar player dapat melihat kondisi lapangan secara mudah. Berikut akan dijelaskan mengenai konsep pada game ini.

Ketika pemain memulai game ini, yang pertama kali ditampilkan adalah menu utama. Pada menu utama terdapat New Game, Load, Setting, Achievement, Exit. Ketika player memilih New Game atau Load, maka yang ditampilkan di layar pertama kali adalah Shop and Assignment. Pada tampilan tersebut, player akan diarahkan untuk mengatur timnya terlebih dahulu. Setelah tim sudah diatur, maka tampilan akan berubah sesuai dengan menu yang dipilih sebelumnya. Apabila, player memilih New Game, maka tampilan akan dilanjutkan ke level 1. Namun, jika player memilih Load, maka tampilan akan dilanjutkan ke level terakhir yang dimainkan oleh player.

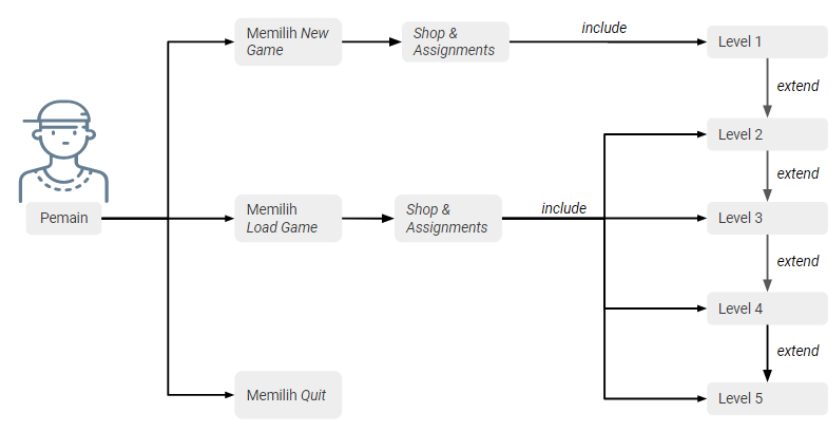

Gambar 1. Use Case Diagram Game

Pada Shop and Assignment terdapat 4 menu yaitu Assignment, Missions, Shop, dan Start. Pada menu assignment, player dapat mengatur timnya. Pada menu mission, player dapat melihat misi di stage tersebut. Player juga dapat mengetahui jumlah zombie dalam satu tim untuk tiap jenisnya, lalu jumlah timnya, dan juga jumlah maksimum zombie yang dipakai dalam keseluruhan tim. Untuk menyelesaikan stage, player wajib menyelesaikan misi yang diberikan tersebut. Pada menu shop, player dapat membeli zombie dan juga items. Player dapat memilih start untuk memulai game. 


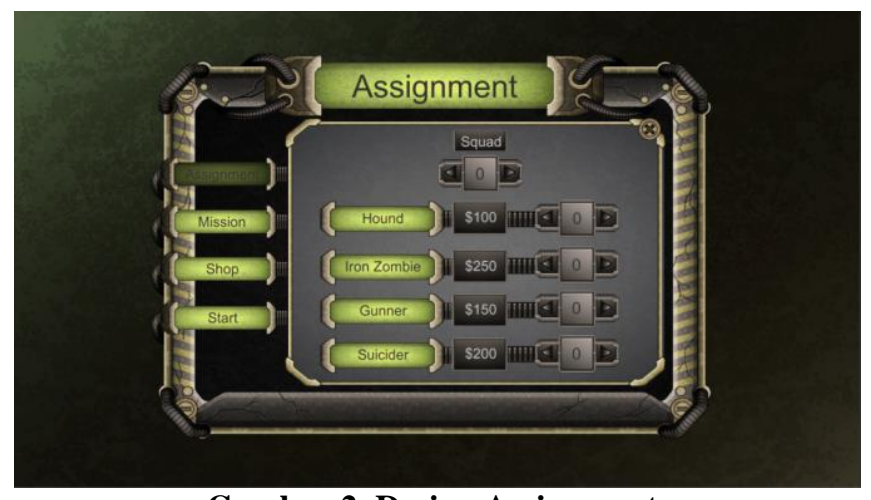

Gambar 2. Design Assignment

Pada saat memulai game, pada tampilan terdapat map, log, dan commands. Button commands adalah fitur yang dapat digunakan player untuk memberikan perintah kepada tim zombie. Sedangkan log menampilkan status lokasi dari setiap tim yang digunakan. Ketika salah satu tim gagal dan musnah, maka log akan menampilkan status bahwa tim tersebut telah tereliminasi.

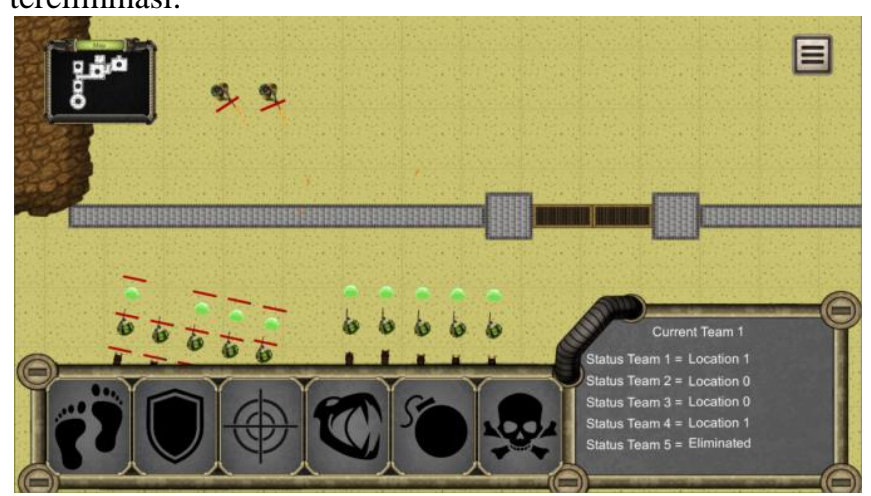

Gambar 3. Design Gameplay

Untuk memberikan perintah pada tim, pertama-tama player memilih ghost general dari tim yang dipilih. Lalu player dapat menginputkan command yang ingin digunakan, yaitu move, shoot, bite, bombs away, massacre, regroup, dan defend.

\section{BEHAVIOR TREE}

A. Behavior Tree pada Player

1. Suicide Zombie

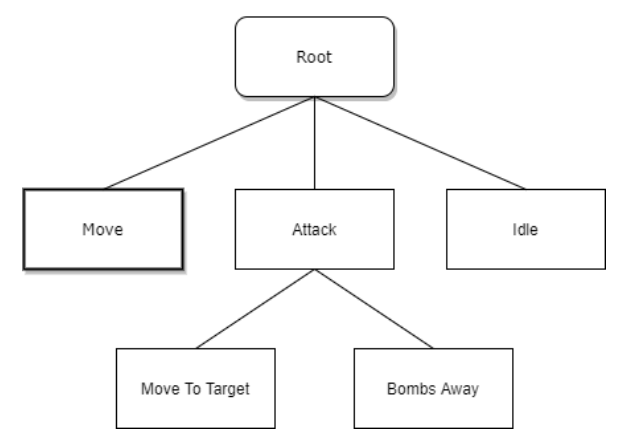

Gambar 4. Behavior Tree Suicide Zombie

Node root merupakan composite tipe selector dimana bergantung input dari player. Root akan menuju ke move, attack, atau idle.
2. Iron Zombie

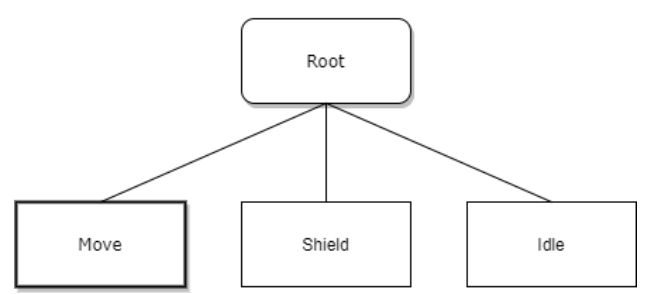

Gambar 5. Behavior Tree Iron Zombie

Karena karakteristiknya yang cukup sederhana, maka iron zombie hanya memiliki empat node, yaitu Root, Move, Shield, dan Idle.

3. Tree Gunner

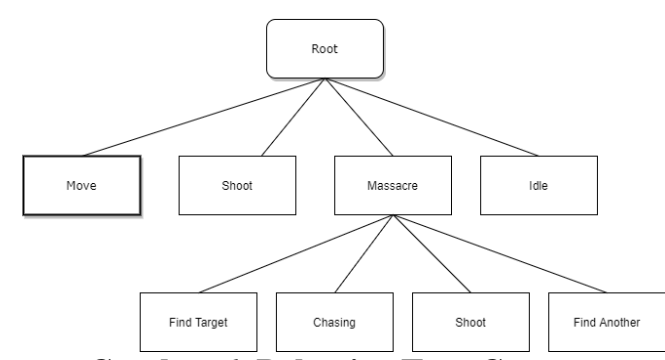

Gambar 6. Behavior Tree Gunner

Pada gunner, terdapat beberapa node dan node root merupakan tipe selector. Dari node root akan dilanjutkan ke node Move, Shoot, Massacre dan Idle.

\section{Hound Dog}

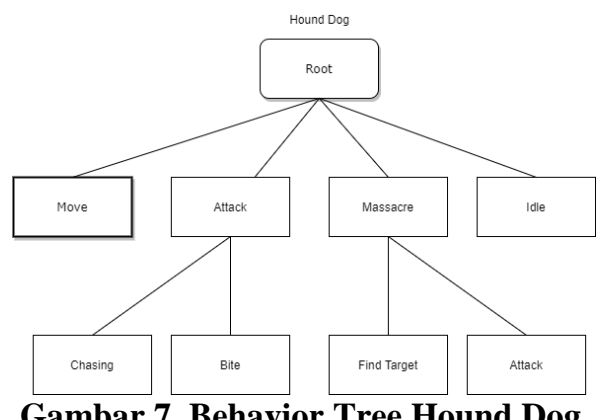

Gambar 7. Behavior Tree Hound Dog

Pada Hound Dog, Node Root bersifat composite tipe selector. Jika tidak ada perintah dari player, maka hound dog akan masuk dalam node idle. Selain node idle, juga ada node move, attack, dan massacre.

B. Behavior Tree pada Enemy

1. Soldier

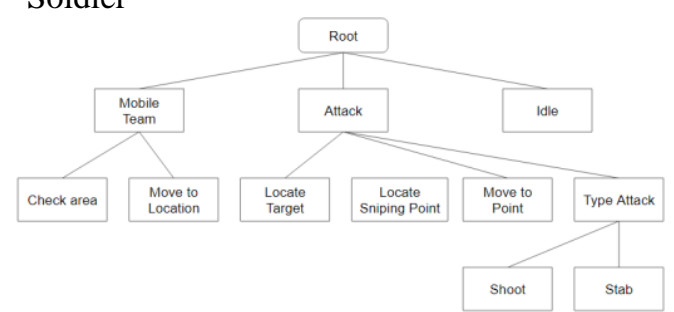

Gambar 8. Behavior Tree Soldier 
Node root dari Behavior Tree Soldier ini merupakan composite tipe selector. Dari node root yang akan diperiksa pertama kali adalah node yang paling kiri, yaitu node mobile team. Jika node mobile attack menghasilkan nilai false, maka akan berlanjut ke node attack. Ketika node mobile team dan node attack mengembalikan value berupa false, maka node idle akan aktif dan selalu mengembalikan nilai true.

2. Doctor

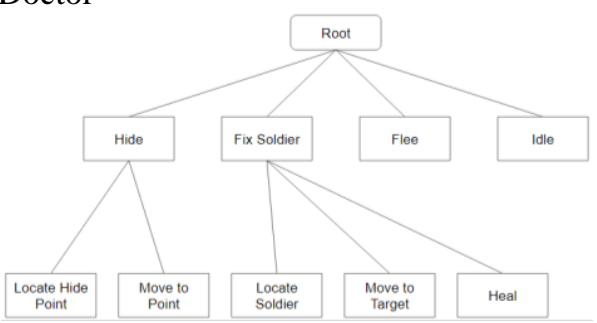

Gambar 9. Behavior Tree Doctor

Node Root dari Behavior Tree untuk doctor ini bersifat composite tipe Selector.

3. Blacksmith

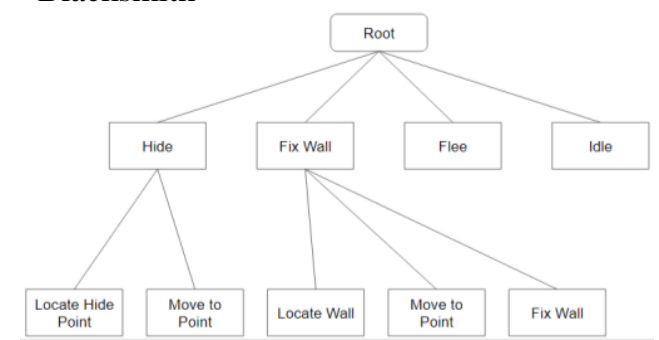

Gambar 10. Behavior Tree Blacksmith

Node Root dari Behavior Tree untuk Blacksmith ini bersifat composite tipe Selector. Dari node root ke node anaknya, selama markas belum ditembus oleh zombie, maka system akan memeriksa dua hal yaitu, apakah ada tembok atau pintu yang rusak dan apakah ada zombie di sekitar situ. Jika tidak ada tembok atau pintu yang rusak dan tidak ada zombie, maka node idle akan mengasilkan value true sehingga proses idle berlangsung.

\section{FUZZY WAYPOINT TACTICS}

Waypoint merupakan suatu tanda lokasi yang diinputkan secara manual maupun otomatis oleh developer. Pada pathfinding, waypoint adalah sebuah posisi yang digunakan oleh algoritma pathfinding untuk menghubungkan dua area yang berbeda. Sehingga karakter tidak perlu berjalan melalui tembok atau mengambil rute yang aneh bagi pemain.

Pada waypoint tactics, waypoint digunakan sebagai sarana bagi developer untuk memberitahu posisi-posisi yang strategis bagi karakter untuk dapat menyelesaikan sebuah tugas. Secara teori, waypoint akan diberikan informasi tambahan agar system dapat membuat keputusan yang lebih kompleks dan informative.

Pada game ini terdapat dua jenis waypoint yang akan dipergunakan. Yang pertama adalah hide waypoint yaitu waypoint yang digunakan untuk berlindung dari serangan musuh dan juga sniping waypoint yaitu waypoint untuk menembak. Untuk mendapatkan hide waypoint, hal yang harus diperhatikan adalah apakah bidikan musuh dapat mengenai karakter. Dan sniping waypoint adalah perlindungan dari bidikan serangan musuh dan juga apakah bidikan sniping waypoint dapat mengenai musuh. Untuk menentukan hasil nilai akhir sniping point, maka system akan menggunakan algoritma fuzzy logic sebagai bantuan pembuat keputusan mengenai sniping waypoint terbaik. Fuzzy Waypoint nantinya akan ditaruh di tempat tempat seperti di balik tembok, pintu atau tempat-tempat lain yang sekiranya dapat memberikan perlindungan yang baik.

Terdapat empat aturan yang akan diterapkan pada fuzzy logic yang akan digunakan yaitu:

- Jika cover (uncovered) atau aim target (can't get target) maka output bad

- Jika cover (covered atau totally covered) dan aim target (can get target) maka output normal

- Jika cover (covered) dan aim target (target spotted) maka output normal

- Jika cover (totally covered) dan aim target (target spotted) maka output good

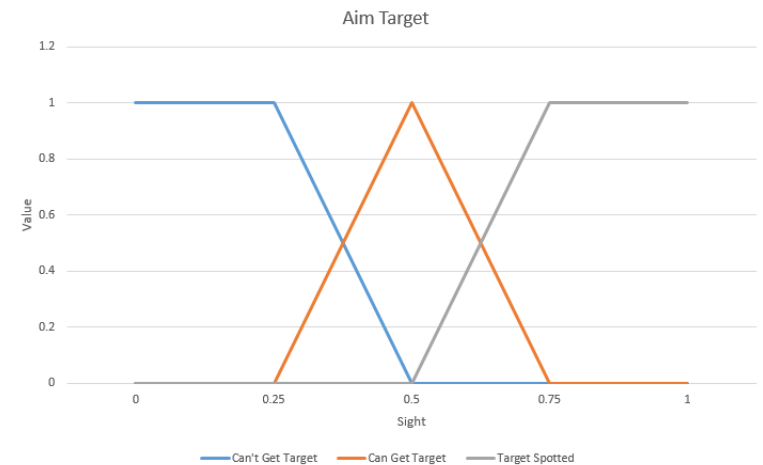

Gambar 11. Fungsi Keanggotaan Nilai Kualitas Bidik

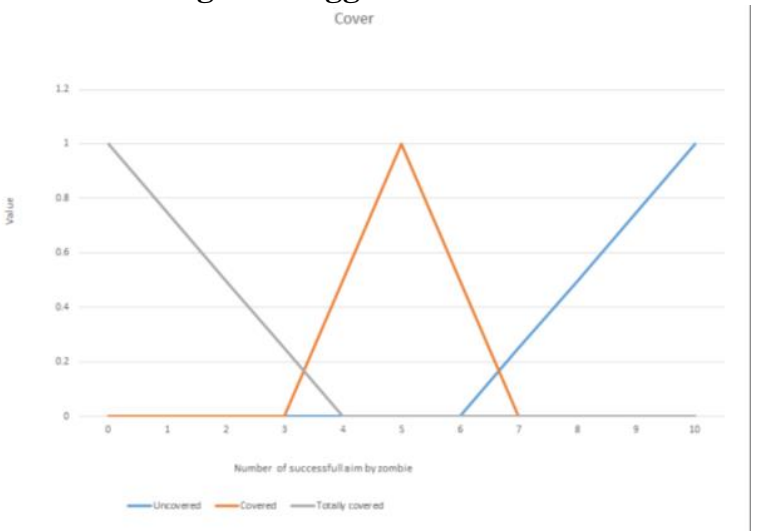

Gambar 12. Fungsi Keanggotaan Nilai Kualitas Cover 


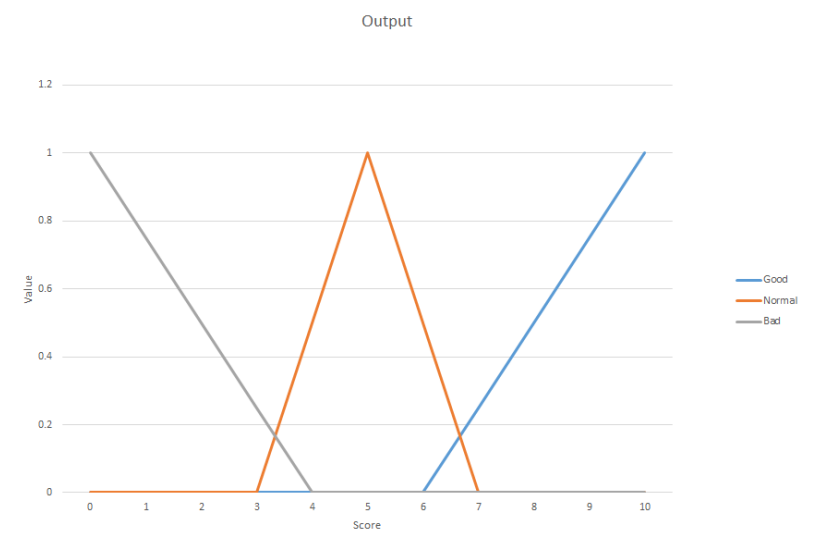

Gambar 13. Grafik Fungsi Keanggotaan Output

$$
\mu[x, a, b]=\left\{\begin{array}{lr}
0 ; & x \leq \mathrm{a} \\
(x-\mathrm{a}) /(\mathrm{b}-\mathrm{a}) ; \mathrm{a} \leq & x \leq \mathrm{b} \\
1 ; & x \geq \mathrm{b}
\end{array}\right.
$$

Formula 1 digunakan apabila bentuk kategorinya berbentuk seperti kategori target spotted pada grafik fungsi keanggotaan aim target. Variable a merupakan nilai kualitas aim target terendah pada kategori target spotted dan variable $\mathrm{b}$ adalah nilai kualitas aim tertinggi pada kategori target spotted. Apabila nilai kualitas cover berada diantara a atau b maka menggunakan rumus $(\mathrm{x}-\mathrm{a}) /(\mathrm{b}-\mathrm{a})$ dimana $\mathrm{x}$ adalah nilai kualitas cover. Nilai cover akan bernilai 0 apabila sama dengan a dan nilai 1 apabila sama dengan $b$.

$$
\mu[x, a, b]= \begin{cases}(\mathrm{b}-\mathrm{x}) /(\mathrm{b}-\mathrm{a}) ; \mathrm{a} \leq x & \leq \mathrm{b} \\ 0 ; & \mathrm{x} \geq \mathrm{b}\end{cases}
$$

Rumus di atas digunakan apabila bentuk kategorinya berbentuk seperti kategori can't get target pada grafik fungsi keanggotaan aim target. b merupakan nilai kualitas aim target terendah pada kategori can't get target dan a adalah nilai kualitas aim tertinggi pada kategori can't get target. Apabila nilai kualitas cover berada pada a atau b maka menggunakan rumus $(b-x) /(b-a)$ dimana $x$ adalah nilai kualitas cover. Nilai cover akan bernilai apabila sama dengan $b$.

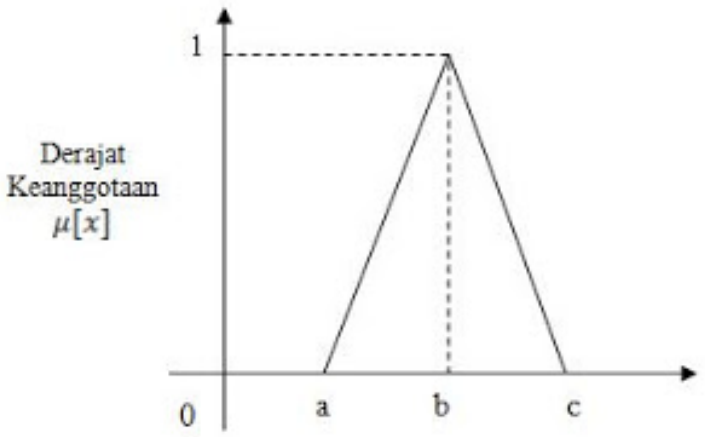

Gambar 16. Representasi Kurva Segitiga

$$
\text { triangle }(x: a, b, c)= \begin{cases}0 & x<a \\ (x-a) /(b-a) & a \leq x \leq b \\ (c-x) /(c-b) & b \leq x \leq c \\ 0 & x>c\end{cases}
$$

Rumus di atas memiliki bentuk segitiga seperti bentuk garis kategori pada output. Dapat dilihat di gambar 5.4, titik a adalah titik awal kategori dengan nilai 0 , lalu $\mathrm{b}$ merupakan merupakan titik tertinggi dengan nilai 1 dan $\mathrm{c}$ adalah titik akhir dengan nilai 0 . Apabila nilai kualitas berada pada $b$ dan a maka menggunakan rumus $(x-a) /(b-a)$. Apabila berada di posisi $(\mathrm{c}-\mathrm{x}) /(\mathrm{c}-\mathrm{b}) . \mathrm{X}$ adalah nilai kualitas waypoint. Dan apabila $\mathrm{x}$ berada di posisi a atau pada posisi $\mathrm{c}$ maka nilai $\mathrm{x}$ adalah 0 .

\section{KESIMPULAN}

Pada penelitian ini telah dikembangkan sebuah game yang memanfaatkan dua buah teknik AI for Games: Fuzzy Way Point Tactics dan Behavior Tree. Kedua hal ini dapat membantu AI pada game War of Zombies sehingga berperilaku lebih cerdas. Beberapa kesimpulan teknis yang didapat selama penelitian antara lain:

1. Pada game bertema strategi seperti war of zombies ini, fuzzy logic sangat effective dalam membantu AI dalam mengambil keputusan bagi setiap karakter

2. Behavior Tree merupakan metode yang sangat baik baik dalam mengatur langkah yang harus diselesaikan oleh karakter atau perilaku karakter.

3. Untuk mencari tempat yang baik dalam melakukan suatu aksi seperti bersembunyi ataupun menembak, waypoint tactic adalah cara yang efektif dan mudah diterapkan bagi developer game.

Beberapa saran untuk penelitian lebih lanjut antara lain adalah:

1. Jenis desain diagram behavior tree akan lebih baik jika dibuat symbol dan keterangan yang lebih lengkap untuk memperjelas alur dan fungsi dari tiap node.

2. Library pendukung untuk mengimplementasikan behavior tree masih tergolong baru sehingga banyak fitur yang dirasa masih bisa ditingkatkan. Penulis berharap dalam waktu kedepan, setelah banyak library mendukung behavior tree, dapat lebih banyak penelitian tentang AI pada Game yang memanfaatkan behavior tree.

\section{DAFTAR PUSTAKA}

I. Millington and J. Funge, Artificial intelligence for games. CRC Press, 2018.

M. Colledanchise and P. Ögren, Behavior trees in robotics and AI: An introduction. CRC Press, 2018.

M. Nicolau, D. Perez-Liebana, M. O'Neill, and A. Brabazon, "Evolutionary behavior tree approaches for navigating platform games," IEEE Trans. Comput. Intell. AI Games, vol. 9, no. 3, pp. 227-238, 2016.

P. A. Lindsay, S. Kromodimoeljo, P. A. Strooper, and M.

Almorsy, "Automation of test case generation from behavior tree 
requirements models," in 2015 24th Australasian Software Engineering Conference, 2015, pp. 118-127.

[5] P. A. Lindsay, "Behavior trees: from systems engineering to software engineering," in 2010 8th IEEE International Conference on Software Engineering and Formal Methods, 2010, pp. 21-30.

[6] L. Lidén and others, "Strategic and tactical reasoning with waypoints," 2002.

[7] A. C. Prasetyo, M. P. Arnandi, H. S. Hudnanto, and B. Setiaji, "Perbandingan Algoritma Astar dan Dijkistra Dalam Menentukan Rute Terdekat," Sisfotenika, vol. 9, no. 1, pp. 36-46, 2019. 